\title{
A QUESTÃO DA ALTERIDADE NO “PRIMITIVISMO ARTÍSTICO”
}

\author{
Arley Andriolo ${ }^{1}$
}

\section{Resumo}

Desde 1938, com a publicação do livro de Robert Goldwater, a noção de "primitivismo artístico" evidenciava a visada do artista europeu para as obras plásticas africanas. Em 1984, essa relação foi reforçada com a exposição Primitivism in XXth century art, organizada por William Rubin. Alguns críticos dessa associação mostram que o campo perceptivo daqueles artistas não se dirigia apenas para os habitantes da África, mas para uma série de personagens, dentre os quais, ciganos, prostitutas, loucos e camponeses. Meu objetivo será o de rever essa problemática para propor uma reflexão metodológica que considere a questão da alteridade, particularmente, enfocando a emergência diante do artista de uma multiplicidade de outros a solicitar o seu olhar.

Palavras chaves: Primitivismo; Alteridade; Percepção; História da Arte (séc. XX).

Nos anos 1920 e 1930, o "caráter primitivo" da arte moderna já ocupava muitos intelectuais, dentre os quais Gonçalo Lafora (1927), Osório Cesar (1934), Meyer Schapiro (1937) e Mário de Andrade (1938). De modo concreto, foi a publicação, em 1938, do livro de Robert Goldwater, Primitivism in modern art ("Primitivismo na arte moderna"), que marcou essa noção na história da arte. Nessa obra, o autor afirmava que Paul Gauguin e outros de sua geração foram os precursores do "primitivismo artístico", anteriores à famosa tela de Picasso, conferindo, assim, um sentido histórico e cronológico para a presença de elementos "primitivos" na arte.

$\mathrm{Na}$ introdução de seu texto, Goldwater (1986, p. xxiii) dizia que o agrupamento de artistas e obras de arte, "originalmente determinado pelo desenvolvimento histórico das várias escolas, visava ser justificado em termos da história do primitivismo". Esse processo paralelo de expansão, está representado nas quatro divisões de seu estudo, delimitando os quatro capítulos, intitulados na seqüência como: 1) "primitivismo romântico" (Gauguin e os fauves); 2) "primitivismo emocional" (Die Brüke e Blaue Reiter); 3) "primitivismo intelectual" (Picasso e pintura abstrata); 4) "primitivismo do subconsciente" (Klee e Miró frente aos desenhos infantis, Dada e Surrealismo). Não obstante as "afinidades" entre esses grupos, Goldwater não identifica o "primitivismo" a uma escola específica, ou a um período da história da pintura. Ainda assim, considera-o um fenômeno histórico, psicológico e formal notável. Trata-se, no entender daquele autor, de uma mudança de atitude no sentido do "verdadeiro primitivo"; o aborígine ou pré-histórico, seja da África e da Oceania, seja pré-colombiano.

O pressuposto subjacente à tese de Goldwater, conforme procurou circunscrever Gill Perry (1998, p. 3), diz respeito a uma tendência "primitiva" interna à arte moderna, que deveria se tornar um aspecto distintivo do "moderno", marcando mesmo a auto-imagem do artista como responsável por uma atividade expressiva mais pura. Décadas depois, o livro de Jean Laude, La peinture française et "l'art nègre" (1905-1914) (“A pintura francesa e a

\footnotetext{
1 Professor doutor do Departamento de Psicologia Social e do Trabalho do Instituto de Psicologia da Universidade de São Paulo. Pesquisador do Laboratório de Estudos em Psicologia da Arte no mesmo Instituto. Bacharel em História, FFLCH-USP, doutor em Psicologia Social, IP-USP. E-mail:arley@,usp.br
} 
'arte negra"'), de 1968, e a exposição no Museu de Arte Moderna de Nova York, organizada por William Rubin e intitulada Primitivism in XXth century art ("Primitivismo na arte do século XX"), em 1984, completaram e reforçaram os fundamentos do "primitivismo" para a arte daquele início de século. Nesse contexto, o "primitivo" é resignificado na história da arte, ampliando sua acepção corrente que referia as obras flamengas e italianas dos séculos XIV e XV, ditas pré-renascentistas, ou as produções précolombianas e de antigas culturas como a egípcia, a persa, a japonesa, entre outras, consideradas menos sofisticadas que as da civilização européia.

Convém lembrar que a tópica do "primitivismo", concebida como um fenômeno cultural, não se limitava aos artistas, embora seja sobre eles que recaia o rótulo de "primitivistas". Nessa perspectiva, foi escrito o livro de Philipe Dagen (1998). Ao notar uma unidade do "primitivismo" nas vanguardas artísticas e literárias, partilhada de maneiras diversas entre romancistas, etnógrafos e críticos, esse autor propôs descrever tal diversidade em seu livro intitulado Le peintre, le poète, le sauvage: les voies du primitivisme dans l'art français ("O pintor, o poeta, o selvagem: as vias do primitivismo na arte francesa"). Conforme Dagen, por exemplo, Picasso e André Salmon podem ser pensados por meio da leitura de Félicien Fagus e de Paul Claudel; bem como Gauguin a partir da leitura de Barbey d'Aurevilly, sob a influência de Charles Morice. Essa análise não foi empreendida tanto por Goldwater quanto por Rubin, devido a uma indiferença baseada no prejulgamento que supõe a pouca ou inexistente leitura entre os artistas. Também críticos desconhecidos hoje, tais como Marius-Ary Leblond et Charles Morice, merecem ser reintegrados, bem como os escritos de Ernst Grosse, Les débuts de l'art, primeiro texto em francês sobre a questão das origens da arte.

Para Dagen (1998, p. 7), a literatura acerca do "primitivismo" na França procede por assimilações e confusões. O "primitivo" é representado em graus cambiáveis de culturas e de obras de arte para além do saber do etnólogo: "Sem dúvida Picasso se entregou ao Museu do Trocadero. Sem dúvida Gauguin morreu na Oceania. Mas Picasso foi também ao Louvre, onde estão os quadros de 'primitivos' italianos. Mas Gauguin tinha também se hospedado antes na Bretanha". Daí a indagação marcante de Charles Morice: "Nós estamos no dia seguinte de alguma coisa. Estamos nós na véspera de alguma coisa?" (citado por Dagen, 1998, p. 8).

De fato, essa percepção do tempo entre os intelectuais emergia desde o século XVIII, quando "primitivo" e "selvagem" representavam um movimento de interesse por um espaço exterior à Europa - África, América, Oceania - e também um espaço interior a ela - camponeses, crianças e loucos (Rhodes, 1999). No final do século XIX, o significado atribuído ao "primitivo" propõe a observação das obras provenientes de regiões colonizadas pelos países europeus como mais simples e inferiores em relação àquelas dos países colonizadores. Desde então, a noção de "primitivo" serve para expressar uma relação e uma subordinação.

Conforme a abordagem elaborada a partir de considerações foucaultianas, Perry configura o "primitivismo" como uma complexa rede de discursos sociológicos, ideológicos, estéticos, científicos, antropológicos, políticos e legais, tecida sobre relações de poder. Em suas palavras:

Por volta da virada do século, aquilo que era descrito como primitivo abrangia com freqüência os produtos de um país recém-colonizado. Dito de forma muito simples, uma leitura de Les demoiselles inspirada pela teoria dos discursos reduziria os significados 
associados com o estilo e as intenções do artista e com a superfície pintada, porque eles seriam vistos basicamente como efeitos dos discursos políticos mais gerais do colonialismo, inclusive os discursos ocidentais contemporâneos sobre a África, que estão inscritos na pintura (Perry, 1998, p. 4).

O conceito de "primitivo", nesse contexto, oscila entre um valor pejorativo e outro positivo, ambos estereotipados. Por um lado, a cultura burguesa e o colonialismo europeu construíam a imagem do outro incivilizado nos museus etnográficos. Por outro lado, criava-se a idéia de "pureza" da "vida primitiva", numa concepção romântica, desenvolvida por exemplo pelo filósofo alemão Herder, exaltando o saber popular (Perry, 1998, p. 6). Por meio dessa análise, bem como outros estudiosos do final do século XX (Foster, 1996; Rhodes, 1997; Dagen, 1998), evidenciou-se o eurocentrismo daquele momento, a partir do qual se produziu a ideologia do "primitivismo" como parte do processo político e econômico do imperialismo, provocando repercussões nas idéias estéticas correntes, em termos como "arte primitiva"; "arte negra"; "arte tribal"; etc.

\section{A inversão do "primitivismo" na arte}

A circulação da idéia de "primitivo" tem relação com aquilo que a Psicologia Social chamou de estereótipo e que o historiador Sander Gilman (1985, p. 15) fez observar como uma construção histórica, com base na ansiedade e no ajustamento da figura mental das pessoas e dos objetos segundo categorias de "bom" e "mau", num ato de proteção, mas que poderemos também considerar em formas de dominação. A imagem ilusória que criamos do mundo divide-o, respectivamente entre nós e os outros, podendo mesmo oscilar do medo à glorificação do outro. Essa experiência de alteridade é fundamentalmente dialética: por um lado, a ciência referia-se ao "primitivo" como menos evoluído, numa leitura social do darwinismo, por outro, intelectuais críticos à sua própria cultura representavam-no como símbolo de pureza.

Neste último caso, enquadra-se o "primitivismo" dos artistas, os quais, a partir de uma atitude oposta à do cientificismo, esboçam uma prática artística muitas vezes subversiva no contato com o outro. A alteridade da arte, na virada do século, conduziu os artistas a lugares distantes, como Gauguin na Oceania, ou a lugares escondidos, como os manicômios visitados por Max Ernst; Lasar Segall, antes de instalar-se no Brasil, visitou o sanatório de Dresden onde desenhou a face de pacientes nos moldes de máscaras africanas. Aqueles artistas eram "primitivistas", no dizer de Colin Rhodes (1997, p. 20), porque convertiam o estereótipo negativo em positivo, pois para eles o "primitivo" era aquele que não tinha limites de convenções artísticas: "Dito de outro modo, para o primitivista, o próprio estado primitivo deve ser avaliado como uma perda deplorável, mais do que um simples ponto de partida". Nesse sentido, o primitivismo não é o movimento de um grupo, mas um conjunto de reações, em que os objetos nomeados "primitivos" são instrumentos para os artistas pensarem seus próprios trabalhos (Rhodes, 1997, p. 7). Por isso, considera-se o "primitivismo artístico" em oposição ao "primitivismo científico".

Em face da atitude radical desses artistas, Rhodes afirma: "Essa vontade de rejeitar a coação das convenções culturais pode ser percebida como uma característica comum da maioria dos movimentos artísticos do século XX. Todavia, convém não ver uma expressão de primitivismo senão no caso em que o ideal oposto às convenções consista em um desejo de redescobrir modos de vida menos complexos ou em nostalgia do natural" (Rhodes, 1997, p. 67). Assim, é forçoso notar que o "primitivismo artístico" abrigou o mito do 
"artista marginal", desenvolvendo uma série de representações não apenas dos outros estranhos à Europa, mas também de camponeses, ciganos, loucos, prostitutas, criminosos, artistas de circo, ou seja, sobre o outro do interior de sua própria cultura.

No entanto, a representação tão-somente desses grupos "marginais" não se configura como expressão desse "primitivismo" crítico. Ao fundar-se na crença da originalidade dos grupos que não teriam sido tocados pelo processo de aprendizagem do Ocidente "civilizado", os "artistas primitivistas" seriam aqueles que inverteram o sentido hegemônico de "primitivo", fazendo de um estereótipo negativo uma aspiração para homens e mulheres. No plano da técnica e da observação das obras produzidas por aqueles grupos, o "primitivismo" operava também na transformação do modo de fazer arte, no qual estilo e assunto possuem uma relação dinâmica, um "primitivismo estilístico", prática claramente distinta das representações de "selvagens" do Novo Mundo, ou do orientalismo da academia do século XIX (Rhodes, 1997, pp. 59, 67 e 74).

Não interessará, pois, as representações de grupos considerados não-civilizados por artistas participantes da esfera de influência da academia, porque aquilo que consideravam o outro é visto apenas por fora, sem a interioridade necessária ao "primitivismo artístico" que subverte a própria produção da obra.

\section{Que havia nos ateliês?}

Ora, embora reunidos sob a noção generalista de "primitivismo", há uma distância muito grande entre os internos de hospitais psiquiátricos e os habitantes da Oceania; entre os objetos rituais africanos e as estampas japonesas trazidas à baila pelos impressionistas. Além desses, havia ídolos orientais, calvários bretões, imagens de Épinal, figuras ingênuas em tapetes e vitrais, objetos provenientes de tribos esquimós ou do paleolítico.

Percorrendo catálogos fotográficos, de exposições e de coleções de arte moderna, vê-se obras plásticas das mais variadas cercando o espaço de trabalho daqueles artistas. No caso de Picasso, sabe-se que havia admirado esculturas e máscaras africanas no ateliê de Derain, por intermédio de Vlaminck. Máscaras desse tipo estão colocadas nas primeiras salas de exposição permanente do Museu Picasso. Mais ainda, um registro de Picasso em seu ateliê em Bateau-Lavoir, Paris, de 1908, mostra duas travessas de cumeeira da Nova Caledônia, Oceania. O ateliê do Boulevard de Clichy, onde morou entre 1909 e 1912, estava cheio de esculturas, máscaras, estátuas e fetiches de várias regiões da África. Numa foto registrando Apollinaire em seu ateliê, ao lado do escritor está uma estatueta tiki em madeira, de 72 centímetros, proveniente das ilhas Marquesas. Seu colega Braque, no ateliê de Paris, possuía igualmente diversas esculturas africanas pinduradas nas paredes, conforme registro fotográfico de 1914.

No entanto, além dessas referências, uma fotografia de 1944, feita por Brassaï, mostra num canto uma escultura de Auguste Forestier, conhecido criador da Art Brut que passou a vida internado, período durante o qual esculpiu e construiu diversos objetos e brinquedos de madeira. Havia também pinturas de Henri Rousseau, uma delas comprada por Picasso em 1908, intitulada Retrato de mulher (1895).

Por sua vez, Matisse também colecionava esculturas em madeira vindas da África, a exemplo de uma originária da República do Congo e reproduzida em Rubin (1987, p. 141). Conforme Goldwater (1986, p. 87), tal coleção formou-se entre 1904 e 1906, cujas peças eram originárias da Guiné, Senegal ou Gabão. Nas palavras de Apollinaire, elas 
“demonstram com sua pureza única uma aterradora emoção". Tais peças eram adquiridas numa loja na rua de Rennes, em Paris.

Se em Matisse e Picasso as fontes africanas parecem ser dominantes, noutros artistas outras referências se destacam. André Lhote (1950, p. 315) está entre os primeiros artistas a comprar obras populares nas feiras de antiguidades, demonstrando verdadeiro interesse para as pinturas do aduaneiro Rousseau. Numa fotografia em sua casa, está acompanhado de máscaras penduradas pela parede, dentre elas, está uma máscara africana e três faces realizadas com a composição de conchas por Pascal-Désir Maisonneuve, uma das quais pertence hoje à coleção ABCD de l'Art Brut.

Em Max Ernst a diversidade desses objetos é evidente. $\mathrm{Na}$ foto de Arnold Newman, de 1942, o artista tem a seu lado uma escultura Kachina Zuñi, do Arizona ou Novo-México. Noutra foto do mesmo ano, Ernst está em pé, em meio a várias esculturas kachina. Por outro lado, como se sabe, entre 1910 e 1914, o artista colecionou obras plásticas adquiridas no hospital psiquiátrico de Bonn, demonstrando interesse de publicar um livro com essas imagens. Kandinsky possuía, entre outras, uma cerâmica folclórica russa, reproduzida no Almanaque do Blaue Reiter, que muito se relaciona a suas pinturas no período de 1911 a 1913. As decorações dos ateliês feitas pelo Die Brücke, por volta de 1909, provinham da Índia do século VI, como pinturas budistas de Ajanta, como se pode ver num trabalho de Heckel.

Outros exemplos poderiam ampliar indefinidamente essa lista. O que se evidencia é a multiplicidade de outros representados nas coleções de artistas. Cabe, pois, considerar que "primitivo" não tratava apenas de povos aborígines, embora a tônica dos escritos acerca do "primitivismo" tenha privilegiado essa relação. Com os estudos produzidos a partir das teorias pós-colonialistas, sobretudo na década de 1990 (p. ex. Foster, 1996; Rhodes, 1997; Dagen, 1998; Perry, 1998), podemos entrever aquilo que a observação dos ateliês nos confirma. A multiplicidade das fontes impõe uma reflexão diferente daquela elaborada por Goldwater, Laude e Rubin; a representação da história não se dá sobre uma linha, mas sobre uma rede.

\section{A questão da alteridade do "primitivismo artístico"}

Inicialmente, há pelo menos três formas de pensar o "primitivo" a partir da ótica do artista europeu daquela virada de século: o "primitivo-popular", o "primitivo-selvagem" e o "primitivo-mental". Além dessas, ou pertinente a elas, está o "primitivo-feminino". Como vimos naqueles ateliês, essas noções foram acompanhadas pelo ingresso de obras até então estranhas ao meio artístico oficial, obras de não-arte, as quais anteriormente não eram vistas como "de arte"; um movimento que modificou as posições e as condições das obras no campo das artes visuais ao longo de todo o século XX (Andriolo, 2004).

O "primitivismo artístico" não se constitui, porém, isolando essas formas, embora assim se possa proceder para análises específicas. Tais formas são partes que compõem um conjunto estruturado de relações, instalado no pensamento e nas práticas artísticas, tendo como eixo a questão do outro. Por isso, o "primitivismo artístico" não é um estilo, uma fase, um programa, uma teoria, como considerou o próprio Goldwater na conclusão de seu estudo.

O "primitivismo artístico" é uma relação de alteridade. Com esta afirmação, gostaria de considerar-lo como um campo de possibilidades aberto ao artista das primeiras décadas do século XX, capaz de elevar diante dele personagens estranhos, exóticos e 
instigantes, em suma, o outro. Nesse sentido, o "primitivismo artístico" não é uma coisa em si, um movimento ou um capítulo da história da arte. Sua designação é posterior àquelas práticas, portanto, limitada como todo olhar retrospectivo. A dialética do "primitivismo" não se restringe à relação entre nós e os outros no plano espacial - uma das possibilidades de se pensar a distância -, entre ocidentais e povos aborígines, mas também da negação interna do próprio grupo nomeado europeu; a exemplo de sãos e loucos, ricos e pobres, citadinos e camponeses. Desse modo, considere-se também as distâncias social, econômica e temporal.

Aqueles artistas reorganizavam a seu modo as idéias do século anterior e projetavam novos mundos, resignificando os temas do historicismo, do exotismo, do original. Nesse sentido, ora arriscam-se a olhar o outro de fora, ora habitam o outro e transformam seus próprios modos de ser. A história do "primitivismo artístico" não pode ser apenas narrada pelo encadeamento entre "precursores" e "difusores", porém, a partir da rede de tensões que alimentam essa designação, em suma, da relação contraditória da alteridade fundadora da noção de "primitivo".

\section{Bibliografia}

ANDRADE, Mário de. Curso de Filosofia e História da Arte. São Paulo, mimeo, Centro de Estudos Folclóricos, GFAU, 1955. (curso original de 1938)

ANDRIOLO, Arley. Histórias da "arte marginal": um processo de ambigüidades. In:CAMPOS, A.; VIEIRA, I.; RIBEIRO, M.; HUCHET, S. (orgs.). Anais do XXIV Colóquio do Comitê Brasileiro de História da Arte. Belo Horizonte: C/Arte, 2005. 1 CD ROM.

ANDRIOLO, Arley. Traços primitivos: histórias do outro lado da arte no século XX. Tese de Doutorado, Instituto de Psicologia da Universidade de São Paulo, São Paulo, 2004.

CESAR, Osório. $A$ arte nos loucos e vanguardistas. Pref. Neves-Manta. Rio de Janeiro: Flores \& Mano, 1934.

DAGEN, Philipe. Le peintre, le poète, le sauvage: les voies du primitivisme dans l'art français. Paris: Flammarion, 1998.

FOSTER, Hal. O inconsciente "primitivo" da arte moderna: ou pele branca, máscaras negras. Em Recodificação: arte, espetáculo, política cultural. São Paulo: Casa Editorial Paulista, 1996, pp. 237-268.

GILMAN, Sander L. Difference and pathology: stereotypes of sexuality, race, and madness. Ithaca: Cornell University Press, 1985.

GOLDWATER, Robert. Primitivism in modern art. Cambridge/London: Belknap Press of Harvard University, 1986.

LAFORA, Gonzalo. Dom Juan, los milagros y otros ensayos. Madrid: Biblioteca Nueva, 1927.

LAUDE, Jean. La peinture français (1905-1914) et "l'art nègre": contribuition à l'étude des sources du fauvisme et du cubisme. Vols. 1 e 2. Paris: Klincksieck, 1963.

LHOTE, André. La peinture: le coeur et l'esprit suive de parlons peinture. Paris: Ed. Denoël, 1950.

PERRY, Gill. O Primitivismo e o Moderno. In: HARRISON, C.; FRASCINA, F.; PERRY, G.. Primitivismo, Cubismo, Abstração: começo do século XX. São Paulo: Cosac \& Naif, 1998. 
RHODES, Colin. Le primitivisme et l'art moderne. Paris: Ed. Thames \& Hudson, 1997.

SCHAPIRO, Meyer. A natureza da arte abstrata (1937). In: A Arte Moderna: séculos XIX e XX. São Paulo: Edusp, 1996, pp. 251-276. 